\title{
Life-threatening laryngeal attacks in hereditary angioedema patients
}

Authors' Contribution: A-Study Design B-Data Collection C-Statistical Analysis D-Data Interpretation E-Manuscript Preparation F-Literature Search G-Funds Collection

\author{
Katarzyna Piotrowicz-Wójcik ${ }^{\mathrm{ABDEF}}$, Grzegorz Porębski ${ }^{\mathrm{ACDEF}}$ \\ Department of Clinical and Environmental Allergology, Jagiellonian University Medical College, Krakow, Poland
}

Article history: Received: 04.03.2020 Accepted: 30.03.2020 Published: 31.03 .2020

ABSTRACT: $\quad$ Background: Hereditary angioedema due to $\mathrm{C}_{1}$-inhibitor deficiency $\left(\mathrm{HAE}-\mathrm{C}_{1} \mathrm{INH}\right)$ is a rare genetic disease that runs in the family. As a result of the disease, acute swellings of the subcutaneous tissue and mucous membranes of the digestive and respiratory systems, including the larynx, occur. Any attack of the disease involving the throat and larynx is particularly dangerous and requires knowledge of clinical determinants of the disease and its proper management.

Materials and methods: The study included adult consecutive HAE-C1INH patients having follow-up visits in our centre. The group was examined with a structured clinical questionnaire, concerning the last 6 months and focusing particularly on laryngeal swelling attacks.

Results: 55 subjects (F/M - 35/20, age range-18-76) were included in the study. Laryngeal attacks occurred in 19 individuals (34.5\%): 1-3, 4-6, and $\geq 7$ attacks in 9,8 and 2 patients, respectively, two of whom required intubation. In comparison to other patients, subjects with laryngeal attacks were characterised by significantly more frequent: (1) facial attacks, (2) severe disease activity, (3) the occurrence of female patients, (4) mental stress as a trigger of attacks. All patients with laryngeal attacks had a rescue medication at home and 15/19 (78\%) patients could use it at home. Most of them used plasma-derived C1-inhibitor $17 / 19(89.5 \%)$ and icatibant, 8/19 (42.1\%).

Discussion: HAE-C1INH patients with laryngeal attacks require particular attention. Proper training regarding the identification of these patients, adequate management, access to emergency services and emergency drugs are essential to ensure the safety of subjects with this localization of HAE-C1INH attacks.

KEYWORDS: $\quad$ C1 inhibitor, hereditary angioedema, icatibant, laryngeal attacks

\section{LIST OF ABBREVIATIONS}

ACEI - angiotensin-converting enzyme inhibitors

C1INH - C1-inhibitor

HAE - Hereditary angioedema

HAE-1 - Hereditary angioedema type 1

HAE-2 - Hereditary angioedema type 2

HAE-C1INH - Hereditary angioedema caused by C1-inhibitor deficiency

\section{INTRODUCTION}

Hereditary angioedema caused by $\mathrm{C} 1$-inhibitor deficiency (HAE-C1INH) is a rare genetic disease with autosomal dominant inheritance. The cause of the disease is $\mathrm{C} 1$-inhibitor deficiency (C1INH): quantitative (low level of C1INH antigen) in HAE type 1 (HAE-1) or qualitative (low functional C1INH level) in HAE type 2 (HAE-2) [1]. The deficiency in the C1-inhibitor leads to disinhibition of cleavage of bradykinin from high-molecularweight kininogen by kallikrein and, as a result, to overproduction of bradykinin responsible for vasodilatation and excessive permeability of capillaries. In consequence, angioedema attacks of subcutaneous tissue (most often the face, hands, feet), but also very dangerous edemas of the mucosa of the digestive system, throat and larynx may appear [2]. Attacks occur spontaneously or are induced for instance by stress, mechanical trauma or infection. In patients with HAE-C1INH, it is absolutely necessary to avoid drugs that may intensify bradykinin edema - angiotensin-converting enzyme inhibitors (ACEI) and estrogens [1, 2]. Angioedema usually develops slowly, but if left untreated or treated improperly, it may result in death. Laryngeal attacks are particularly dangerous for patients, that is why the correct diagnosis and appropriate treatment are so important. Undiagnosed laryngeal attacks in the course of HAE$\mathrm{C} 1 \mathrm{INH}$ are characterized by high mortality reaching $50 \%$ [3].

In the diagnosis of hereditary angioedema, plasma levels of C4, $\mathrm{C} 1$-inhibitor antigen and $\mathrm{C} 1$-inhibitor function are measured. Levels of all these parameters are reduced in HAE-1, whereas in HAE$2 \mathrm{C} 1 \mathrm{INH}$ function is reduced, but not $\mathrm{C} 1 \mathrm{INH}$ antigen level (see - supplementary materials) [1]. In the treatment of severe HAE-C1INH attacks in Poland, the supplementation of the missing protein with intravenous C1-inhibitor preparations is used: plasma-derived (Berinert - $20 \mathrm{U} / \mathrm{kg}$, usually $1 \mathrm{amp}$. a $1500 \mathrm{U}$ ) or recombinant human (Ruconest - $50 \mathrm{U} / \mathrm{kg}$, usually 2 amp., a total of $4200 \mathrm{U}$ ), as well as icatibant, a subcutaneous inhibitor of bradykinin B2 receptors 
(Firazyr $-30 \mathrm{mg} / \mathrm{kg}$ ) [2, 4]. When they are lacking, fresh frozen plasma (2-3 units) might be administered. An effectively treated angioedema attack disappears within a few hours. It is important, especially in patients with laryngeal attacks, to administer the drug as soon as possible to stop the edema at an early stage. Rapid administration of the drug is possible thanks to appropriate training of patients and their families in the technique of self-administration of life-threatening emergency treatments. All the above-mentioned drugs are approved for self-administration at home. Laryngeal angioedema in the course of HAE-C1INH is resistant to treatment with glucocorticosteroids and antihistamines, therefore these drugs are not recommended for those patients. All patients with laryngeal attacks, also after administration of appropriate treatment, should be observed in hospital setting $[1,2,5]$.

During a laryngeal attack, apart from ensuring proper treatment, a patient should also be appropriately positioned - with the head slightly backwards to maintain a patent airway. Any manipulation that causes mechanical irritation of the larynx mucosa may increase the swelling, therefore any intubation of a patient should be performed by an experienced physician. In the case of ineffective conservative treatment, tracheotomy or coniotomy is performed [5, 6].

\section{MATERIALS AND METHODS}

Patients: The study included 55 adults (20 men, 35 women) aged 18-76 years (mean age -40 years, SD - 13.5) diagnosed with hereditary angioedema due to C1-INH deficiency, consecutively reporting to the Center of Clinical Allergology University Hospital in Krakow for regular visits and having angioedema attacks in the last 6 months preceding the study. Children $(<18$ years old) and asymptomatic patients were excluded from the study. A group of 19 patients reporting laryngeal attacks within the last six months was separated from the study group. Prior the study, patients signed informed consent of participation. The study was carried out in accordance with the requirements of the Helsinki Declaration and obtained the permission of the local bioethics committee.

Methods: A structured clinical questionnaire was used for a detailed clinical evaluation of patients, including questions about the course and treatment of HAE-C1INH in the last 6 months and focusing particularly on laryngeal swelling attacks. The study group was divided into two subgroups: patients with and without laryngeal attacks. In order to find some clinical features characteristic for patients with laryngeal angioedema attacks, both groups were compared in respect to: frequency and location of all HAE-C1INH attacks, trigger factors, prodromal and accompanying symptoms, treatment and access to self-administered rescue medication. The severity of HAE-C1INH was assessed according to the scale ("severe", "moderate", "mild", "minimal") proposed by Agostoni et al. [7].

Statistical analysis: A two-tailed Chi-square test with Yates' correction and Fisher's exact test were applied to compare the groups. The mean values between groups were compared with Mann-Whitney test. P-value $<0.05$ was considered statistically significant. Statistical analyses were performed using GraphPad Software (La Jolla, CA, USA).
Tab. I. Comparison of the group of patients with and without laryngeal attacks in the course of HAE-C1INH.

\begin{tabular}{|c|c|c|c|}
\hline & $\begin{array}{l}\text { PATIENTS WITH } \\
\text { LARYNGEAL ATTACKS } \\
\text { NO }(\%)\end{array}$ & $\begin{array}{l}\text { PATIENTS WITHOUT } \\
\text { LARYNGEAL } \\
\text { ATTACKS NO (\%) }\end{array}$ & PVALUE \\
\hline Number of subjects & $19(34.5)$ & $36(65.5)$ & ND \\
\hline Mean age & 39.8 lat (SD 14.8) & 40.1 lat (SD 13) & ns \\
\hline Gender (M/F) & $2 / 17(10.5 / 89.5)$ & $18 / 18(50 / 50)$ & 0.009 \\
\hline $\begin{array}{l}\text { Type of HAE-C1INH } \\
\text { (HAE-1/HAE-2) }\end{array}$ & $18 / 1(94.7 / 5.3)$ & $30 / 6(83.3 / 16.7)$ & ns \\
\hline Location of attacks & & & ns \\
\hline abdominal & $18(94.7)$ & $30(83.3)$ & ns \\
\hline peripheral & $19(100)$ & $31(86.1)$ & 0.013 \\
\hline facial & $12(63.2)$ & $9(25)$ & ns \\
\hline $\begin{array}{l}\text { another (chest, neck, } \\
\text { genitals) }\end{array}$ & $12(63.2)$ & $18(50)$ & 0.008 \\
\hline Severe disease activity & $19(100)$ & $23(64)$ & ns \\
\hline Age of onset of attacks & 8.5 lat (SD 6) & 11.6 lat (SD 11.6) & 0.015 \\
\hline Triggers & $17(89.5)$ & $20(55.6)$ & ns \\
\hline mental stress & $15(79)$ & $18(50)$ & ns \\
\hline physical trauma & $13(36.1)$ & 14 (38.9) & ns \\
\hline infection & $8(47.1)$ & $9(50)$ & ns \\
\hline menstruation & & & ns \\
\hline HAE-C1INH in family & $15(79)$ & & \\
\hline $\begin{array}{l}\text { Death related to HAE- } \\
\text { CilNH in family }\end{array}$ & $3(15.8)$ & $13(36.1)$ & \\
\hline
\end{tabular}

\section{RESULTS}

The characteristic clinical determinants of the two groups of patients, with and without laryngeal attacks in the course of HAE-C1INH, observed during the last six months were compared in Tab. I. The number of laryngeal attacks was: 1-3 attacks in 9 patients, $4-6$ in 8 patients, $\geq 7$ attacks in 2 patients. In one individual the number of laryngeal attacks in the last 6 months reach up to 18 . Intubation was performed in 2 respondents, and further 4 patients managed to avoid intubation due to regression of angioedema after the administration of C1-inhibitor preparations. The severity score of the disease, which takes into account location, duration and treatment of attacks, was assessed as "severe" in all patients with laryngeal edema [2, 7]. The factor that most often induced angioedema attacks in both groups was mental stress, but in the group with laryngeal episodes it was significantly more frequent. Similarly, facial edema and female sex occurred significantly more frequently in the group with laryngeal attacks.

Data on the treatment of HAE-C1INH attacks are presented in Tab. II. Patients in both groups most often used plasma-derived $\mathrm{C} 1$-esterase inhibitor and icatibant. All patients in the group with a history of laryngeal angioedema had a rescue medication at home, and $79 \%$ of them administered the medicine themselves or it was given to them by a family member after an appropriate training. A few subjects used tranexamic acid or danazol for the long-term prophylaxis of HAE-C1INH attacks. 
Tab. II. Treatment of patients with laryngeal attacks in the course of HAE-C1INH and a group without laryngeal attacks.

\begin{tabular}{llll} 
& $\begin{array}{l}\text { PATIENTS WITH } \\
\text { LARYNGEAL } \\
\text { ATTACKS NO (\%) }\end{array}$ & $\begin{array}{l}\text { PATIENTS WITHOUT } \\
\text { LARYNGEAL } \\
\text { ATTACKS NO (\%) }\end{array}$ & PVALUE \\
\hline $\begin{array}{l}\text { Emergency medication } \\
\text { (in the last 6 months) }\end{array}$ & $17(89.5)$ & $21(58.3)$ & 0.03 \\
pdC1-INH & $8(42.1)$ & $16(44.4)$ & $\mathrm{ns}$ \\
icatybant & $1(5.3)$ & $3(8.3)$ & $\mathrm{ns}$ \\
rhC1-INH & & & \\
$\begin{array}{l}\text { Long-term prophylaxis } \\
\text { tranexamic acid }\end{array}$ & $2(10.6)$ & $1(2.8)$ & $\mathrm{ns}$ \\
danazol & $2(10.6)$ & $1(2.8)$ & $\mathrm{ns}$ \\
\hline $\begin{array}{l}\text { Rescue medication at home } \\
\text { Self-administration or Adminis- }\end{array}$ & $19(100)$ & $33(91.7)$ & $\mathrm{ns}$ \\
tration by a family member & $15(79)$ & $24(66.7)$ & $\mathrm{ns}$ \\
\hline
\end{tabular}

pd-C1INH-plasma-derived C1INH; rh-C11NH-human recombinant $\mathrm{C}_{1} 1 \mathrm{NH}$; ns-not significant

\section{DISCUSSION}

Among the patients with hereditary angioedema caused by C1-inhibitor deficiency, attacks of laryngeal edema are not uncommon (attacks within the last 6 months in $34.5 \%$ of the study group). Around $50 \%$ of HAE-C1INH patients experience angioedema of the larynx during their lifetime [5]. In 100\% of our patients with laryngeal attacks, the severity of the disease according to Agostoni scale [7] was assessed as severe. This means that all patients have had a high number of attacks not only of the larynx, but also in other locations over the past six months, which indicates that the overall course of the disease in patients with laryngeal swelling episodes is more severe. Our observations show that facial attacks are more common in patients with laryngeal angioedema, which is also described in the literature [5]. The significant predominance of women in the group of patients with laryngeal attacks $(89.5 \%)$ is noteworthy. This may result from estrogen activity, which deteriorates HAE-C1INH and from the anatomical conditions of the larynx in women, namely the higher position of the larynx [6] facilitates faster spread of throat swelling to further parts of the respiratory tract.

A very positive fact is that all patients with laryngeal attacks had a rescue medication at home and nearly $80 \%$ of them were able to administer it themselves or with the help of a family member. This indicates high awareness of the risks associated with the disease. Patients with laryngeal attacks most often used plasma-derived C1-INH (pd-C1INH) and icatibant. Pd-C1INH is the longest used emergency treatment in Poland and patients with dangerous symptoms readily reach for it. A summary analysis of various therapeutic options in the treatment of laryngeal attacks by Bork et al. [8] indicates that intravenous pd-C1INH administered at the full recommended dose could be regarded as the treatment producing the most reliable response. In turn, an apparent advantage of icatibant is the subcutaneous way of its administration, which shortens the time from symptom onset to the start of the treatment, and in consequence reduces the duration and severity of an angioedema attack [9]. The effectiveness of icatibant in laryngeal attacks was confirmed by observations carried out in everyday practice [10]. In the cases of HAE-C1INH larynx edemas, the alarm symptoms that require immediate treatment are: feeling of having a lump and/or feeling of tightness in the throat, swallowing difficulties [11].

HAE-C1INH patients with laryngeal attacks require particular attention. Proper training in dealing with those patients, providing emergency treatment and quick access to emergency care units are necessary to ensure the safety of the patients with this type of HAE-C1INH attacks. The group of patients with laryngeal attacks remaining under the care of our center exemplify and confirm these statements. So far, all our patients have been successfully treated during laryngeal attacks thanks to a properly conducted therapy and appropriate training. In case of recurrent, refractory to glucocorticosteroids and antihistamines laryngeal swellings, especially with an accompanying positive family history, hereditary angioedema due to $\mathrm{C} 1$-inhibitor deficiency should always be taken into account in the differential diagnosis and management (see additional materials) [12, 13, 14].

\section{REFERENCES}

1. Betschel S., Badiou J., Binkley K., Borici-Mazi R., Hébert J. et al.: The International/Canadian Hereditary Angioedema Guideline. Allergy Asthma Clin Immunol., 2019; 15: 72.

2. Maurer M., Magerl M., Ansotegui I., Aygören Pürsün E., Betschel S. et al.: The international WAO/EAACI guideline for the management of hereditary angioedema - the 2017 revision and update. Allergy, 2018; 73(8): 1575-1596.

3. Craig T.J., Wasserman R.L., Levy R.J., Bewtra A.K., Schneider L. et al.: Prospective Study of Rapid Relief Provided by C1 Esterase Inhibitor in Emergency Treatment of Acute Laryngeal Attacks in Hereditary Angioedema. J Allergy Clin Immunol., 2010; 30: 823-829.

4. Longhurst H.: Optimum Use of Acute Treatments for Hereditary Angioedema: Evidence-Based Expert Consensus. Front Med (Lausanne)., 2018; 4: 245.

5. Depetri F., Tedeschi A., Cugno M.: Angioedema and emergency medicine: From pathophysiology to diagnosis and treatment. Eur J Intern Med., 2019; 59: 8-13.

6. Składzień J.: Napady obrzęku krtani u chorych z wrodzonym obrzękiem naczynioruchowym (Hereditary angioedema - HAE). Alergologia Immunologia, 2015; 12(1):5-8.

7. Agostoni A., Aygören-Pürsün E., Binkley K.E., Blanch A., Bork K. et al.: Hereditary and acquired angioedema: problems and progress: proceedings of the third $\mathrm{C} 1$ esterase inhibitor deficiency workshop and beyond. J Allergy Clin Immunol., 2004; 114 (3 Suppl): S51-131.

8. Bork K., Bernstein J.A., Machnig T., Craig T.J.: Efficacy of Different Medical Therapies for the Treatment of Acute Laryngeal Attacks of Hereditary Angioedema due to C1-esterase Inhibitor Deficiency. J Emerg Med., 2016; 50(4): 567-580.

9. Maurer M., Aberer W., Bouillet L., Caballero T., Fabien V. et al.: Hereditary angioedema attacks resolve faster and are shorter after early icatibant treatment. PLoS One, 2013; 8(2): e53773.

10. Longhurst H.J., Aberer W., Bouillet L., Caballero T., Maurer M. et al.: The Icatibant Outcome Survey: treatment of laryngeal angioedema attacks. Eur J Emerg Med., 2016; 23(3): 224-227.

11. Bork K., Hardt J., Witzke G.: Fatal laryngeal attacks and mortality in hereditary angioedema due to C1-INH deficiency. J Allergy Clin Immunol., 2012; 130: 692-697.

12. Lenschow M., Bas M., Johnson F., Wirth M., Strassen U.: A score for the differential diagnosis of bradykinin- and histamine-induced head and neck swellings. Eur Arch Otorhinolaryngol., 2018; 275(7): 1767-1773.

13. Szkiełkowska A., Miaśkiewicz B., Krasnodębska P., Skarżyński H.: Objectification of the severity of Reinke's edema. Otolaryngol Pol., 2014; 68(6): 287-292.

14. Aygören-Pürsün E., Magerl M., Maetzel A., Maurer M.: Epidemiology of Bradykinin-mediated angioedema: a systematic investigation of epidemiological studies. Orphanet J Rare Dis., 2018; 13(1): 73. 


\section{SUPPLEMENTARY MATERIALS}

\section{KEY POINTS:}

- Hereditary angioedema (HAE) is rare disease characterized by recurrent episodes of swelling in the absence of concomitant urticaria or use of medication known to induce angioedema;

- Angioedema attacks involve the extremities, intestinal tract, upper airways or genitals. Laryngeal attacks are potentially life-threatening. Attacks do not respond to typical anti-allergic treatment;

- The most common HAE type is hereditary angioedema due to C1-inhibitor (HAE-C1INH) deficiency (estimated prevalence 1:50 000 in general population). Deficiency in C1INH lead to increased production of bradykinin, mediates capillary permeability, and in consequence angioedema;

- The other HAE types are much less prevalent and involve types either with known genetic background (HAE-F12, HAE-PLG, HAE-ANG) or HAE-UNK (a family history of angioedema without a genetic variant associated with the disease).

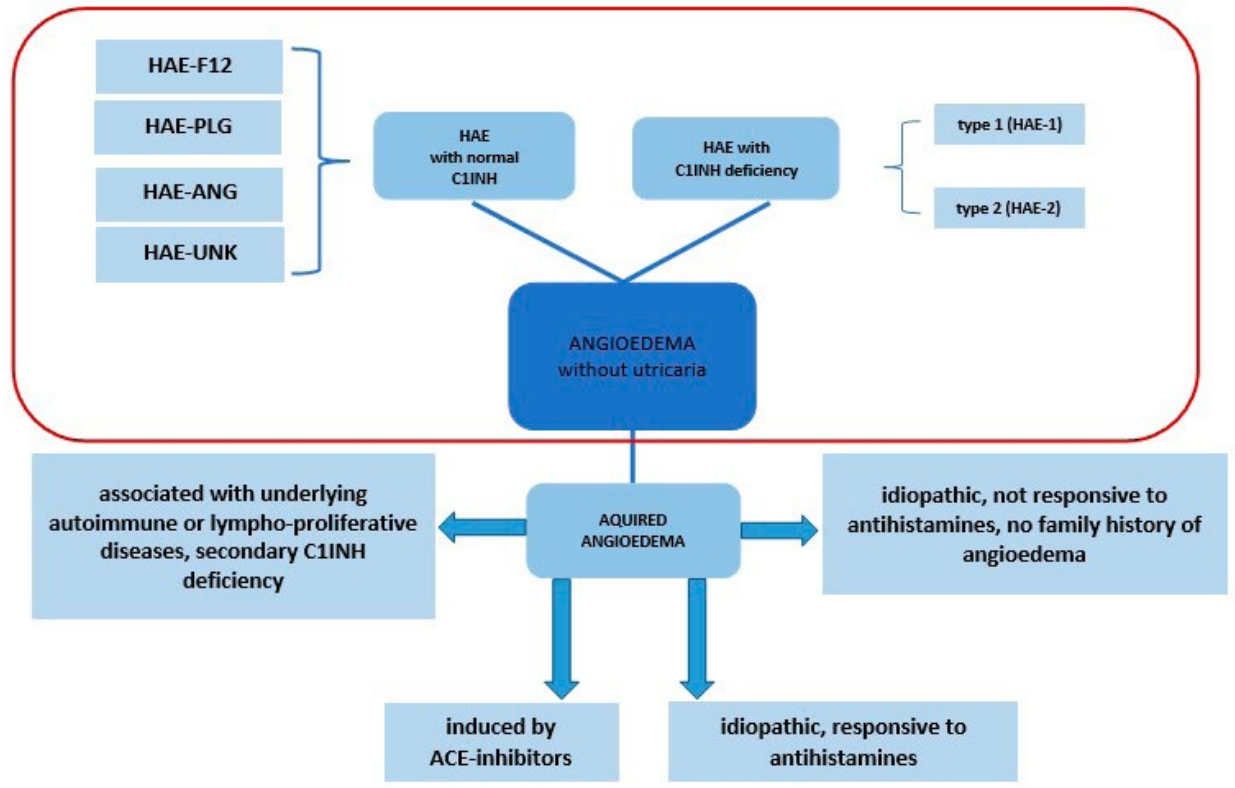

\begin{tabular}{|c|c|c|c|c|}
\hline \multicolumn{5}{|c|}{ Laboratory findings in HAE: } \\
\hline & C4 & $\begin{array}{l}\text { C1INH } \\
\text { level }\end{array}$ & $\begin{array}{l}\text { C1INH } \\
\text { function }\end{array}$ & Gene mutation \\
\hline HAE-1 & $\downarrow$ & $\downarrow$ & $\downarrow$ & SERPING-1 \\
\hline HAE-2 & $\downarrow$ & $\mathbf{N}$ & $\downarrow$ & SERPING-1 \\
\hline HAE-F12 & \multicolumn{3}{|c|}{$\mathbf{N}$} & factor 12 \\
\hline HAE-PLG & \multicolumn{3}{|c|}{$\mathbf{N}$} & plasminogen \\
\hline HAE-ANG & \multicolumn{3}{|c|}{$\mathbf{N}$} & angiopoietin-1 \\
\hline HAE-1-UNK & \multicolumn{3}{|c|}{$\mathbf{N}$} & unidentified $^{*}$ \\
\hline
\end{tabular}

Evaluation of angioedema in emergency conditions life-threatening symptoms in upper airways

- dysphonia

- stridor

- feeling of having a lump,

- feeling of tightness in the throat,

- swallowing difficulties.

- lingual edema.

\begin{tabular}{|l|l|l|}
\hline \multicolumn{3}{|c|}{ Therapies for HAE-C1INH acute attacks* } \\
\hline Treatment & Mechanism of action & Dose and route of administration \\
\hline icatibant & antagonist of bradykinin 2 receptors & $\begin{array}{l}30 \mathrm{mg} \text { subcutaneous injection, dose- } \\
\text { adjusted for adolescents }<65 \mathrm{~kg} \text { and children } \\
>2 \text { years }\end{array}$ \\
\hline pd-C1INH & replaces C1INH & $20 \mathrm{U} / \mathrm{kg}$ intravenous \\
\hline rh-C1INH & replaces C1INH & $\begin{array}{l}4200 \mathrm{U}(\geq 84 \mathrm{~kg}), 50 \mathrm{U} / \mathrm{kg}(<84 \mathrm{~kg}), \\
\text { intravenous }\end{array}$ \\
\hline FFP & replaces C1INH & $2 \mathrm{U}(<90 \mathrm{~kg}), 3 \mathrm{U}(>90 \mathrm{~kg})$ \\
\hline
\end{tabular}

pd-C1INH, plasma-derived C1INH; rh-C1INH, human recombinant C1INH; FFP, fresh frozen plasma *approved and reimbursed in Poland

REFERENCE CENTER in POLAND: Center of Clinical and Environmental Allergology, University Hospital in Krakow, Botaniczna 3, 31-503 Krakow, Poland; phone: 124248650

References: Betschel S et al. J Allergy Clin Immunol Pract. 2020;8: 310-317. Bork K et al. J Allergy Clin Immunol, 2012; 130: 692-697. Cicardi M et al. Intern Emerg Med, 2014; 9: 85-92. Moellman JJ et al. Academic Emergency Med 2014; 21: 469-484. Porebski G et al, Polish Journal of Allergology 2018; 5, 2: 109-120. Veronez CL et al. Curr Opin Allergy Clin Immunol. 2020 Feb 18. doi: 10.1097/ACI.0000000000000633 


\begin{tabular}{lll}
\hline Word count: $2260 \quad$ Tables: 2 & Figures: - & References: 14 \\
\hline
\end{tabular}

DOl: $\quad$ 10.5604/01.3001.0014.0619 Table of content: https://otolaryngologypl.com/issue/12703

Copyright: Copyright @ 2019 Polish Society of Otorhinolaryngologists Head and Neck Surgeons. Published by Index Copernicus Sp. z o.o. All rights reserved

Competing interests: The authors declare that they have no competing interests.

2 The content of the journal „Polish Society of Otorhinolaryngologists Head and Neck Surgeons” is circulated on the basis of (6) Then Access which means free and limitless access to scientific data.

(c) (i) (9)(2)

Corresponding author:

Cite this article as: Piotrowicz-Wojcik K., Porebski G.: Life-threatening laryngeal attacks in hereditary angioedema patients; Otolaryngol Pol 2020; 74 (2): $42-47$

This material is available under the Creative Commons - Attribution 4.0 GB. The full terms of this license are available on: http://creativecommons.org/licenses/by-nc-sa/4.0/legalcode

Grzegorz Porebski (ORCID: 0000-0002-6146-0188); Department of Clinical and Environmental Allergology, Jagiellonian University Medical College, Krakow, Poland; Botaniczna Street 3, 31-503 Krakow, Poland; Phone: +48 (12) 4248638 ; E-mail: g.porebski@uj.edu.pl 
